\title{
Creating tasks in a less-commonly taught language for an open educational resource: Why the CEFR is important for Irish
}

\author{
Colm Ó Ciardúbháin ${ }^{1}$ and Mairéad Nic Giolla Mhichíl ${ }^{2}$
}

\begin{abstract}
If teachers of Less-Commonly Taught Languages (LCTLs), such as Irish, are to make use of Open Educational Resources (OERs) and many other CALL tools, then there must be an appropriate adaptation of the Common European Framework of Reference (CEFR) in that LCTL. The need to be "Bologna-compliant" has seen language courses and syllabuses in Ireland being set out according to Common Reference Levels of the CEFR. Many CALL tools and resources which have been developed in a European context are underpinned by the Common Reference Levels of the CEFR. This symbiosis means that, in many cases, making use of one cannot be done properly without due regard to the other. In Ireland, however, the applications of the CEFR and integration of CALL have been engaged in separately for the most part. As the demand for CALL grows in Ireland, the lack of an Irish language adaptation of the CEFR becomes more problematic. This paper presents a case study on the Irish language partner on the SpeakApps project (http:/www.speakapps.eu/). It will begin with a brief literature review on implementing CALL principles in LCTLs, and application of the CEFR to LCTLs. It then examines the experiences of the Irish partner in designing online oral production and interaction tasks according to the CEFR to be used on language courses that have not previously used CEFR learning goals or reference levels. In this paper we conclude that adaptations of the CEFR's Common Reference Levels with clear illustrative descriptors are needed before teachers of LCTLs can optimise OERs and other CALL tools.
\end{abstract}

Keywords: Irish language, CEFR adaptation, open educational resource.

1. Dublin City University, Ireland; colm.ociardubhain@dcu.ie.

2. Dublin City University, Ireland; mairead.nicgiollamhichil@dcu.ie.

How to cite this article: Ó Ciardúbháin, C., \& Nic Giolla Mhichíl, M. (2014). Creating tasks in a less-commonly taught language for an open educational resource: Why the CEFR is important for Irish. In S. Jager, L. Bradley, E. J. Meima, \& S. Thouësny (Eds), CALL Design: Principles and Practice; Proceedings of the 2014 EUROCALL Conference, Groningen, The Netherlands (pp. 261-266). Dublin: Research-publishing.net. doi:10.14705/rpnet.2014.000228 


\section{Introduction}

The CEFR and the OERs present a number of opportunities for both the teaching and the learning of LCTLs. In spite of this, it is acknowledged that the application and implementation of the CEFR varies greatly across LCTLs (Lotti, 2007). The CEFR provides LCTLs (as it does with other languages) with a meta-framework to communicate competencies and proficiencies as well as providing a mechanism to benchmark linguistic outcomes (Council of Europe, 2001, p. 5). The proliferation of the CEFR within teaching and learning of the Irish language to date can be described as limited, although a number of initiatives are under way to integrate the CEFR at various levels across the Education System. It is argued in this paper, however, that the wider implementation of the CEFR for the Irish language should coincide with an adaptation of the CEFR to reflect the socio-linguistic context of the language.

The adaptation of the CEFR is important in the case of the Irish language, particularly if considered in the context of the proliferation of OERs as means by which learners and teachers have access to language specific resources underpinned or benchmarked to the CEFR. OERs are defined as resources released under open licences for the use and re-use by a number of stakeholders such as teachers, learners or researchers for both academic and non-academic learning, usually in a not-for-profit capacity (D’Antoni, 2009; Martinez, 2010; Smith \& Casserly, 2006). OERs can be considered to embody the tradition of education of the sharing and dissemination of knowledge for the public good. OERs are viewed by Blyth (2013) as allowing stakeholders to create their own "knowledge ecology", which is of particular relevance to LCTLs, where economies of scale of learners and teachers may be potentially limited (p. 3). In such cases, investment in language resources are significantly more costly than would be the case where significant scale exists. OERs, thus, present an opportunity for languages such as Irish to develop open repositories of language resources. However, these resources should be cognisant and reflective of the socio-linguistic context of the language.

\section{Method}

\subsection{CEFR, the Irish language education and OERs}

In the last seven years, the CEFR has gained some traction in the Irish education system. In Higher Education, an initiative to design a core syllabus for the teaching of Irish at third level is benchmarked at learners achieving B2 on its completion (Walsh \& Nic Eoin, 2010). An Meitheal um Theagasc na Gaeilge ar an Tríu 
Leibhéal (the task force for teaching Irish at third level) designed a syllabus for each of the three years of Irish language university education. These syllabuses, as well as sample tasks and accompanying audio visual material, are available online. At second level, The Teaching Council of Ireland (2013) has stipulated that individuals applying to become post-primary language teachers must demonstrate B2.2 proficiency in the European language they wish to teach. The National Qualifications Authority of Ireland asserts that students who pass language subjects in the post-primary terminal examinations (The Leaving Certificate) will have achieved B1 (NQAI, 2007, p. 8). A further evaluation initiative, Teastas Eorpach na Gaeilge known as TEG (The European Certificate in Irish), has made significant use of the CEFR. Individuals who successfully complete the TEG exams can receive a general language proficiency certificate. TEG is identified as being "broadly based on the Common European Framework of Reference for Languages" (Teastas Eorpach na Gaeilge, 2006, para. 2). Resources are available and include syllabi based on the levels of the CEFR as well as the lessons plans, worksheets and accompanying audio visual material ${ }^{3}$. For instance, the Clilstore website (multidict.net), developed as part of the European project Tools for CLIL Teachers, allows teachers to create language learning units, categorised according to the CEFR, which facilitates content and language integrated learning. The website also contains a repository of these learning units (Gimeno, Ó Dónaill, \& Zygmantaite, 2013).

Despite these initiatives and in comparison to other LCTLs, the integration and influence of the CEFR in Irish language teaching is unclear. Lotti's (2007) report into the take-up of the CEFR in LCTLs was that "it was not possible to gather enough information about the language education situation for Irish in Ireland" (p. 10). While the CEFR is a language-independent instrument, difficulties in using the CEFR for regional or minority languages are described by Lotti (2007) as firstly centering on the CEFR being designed primarily for foreign language learning, whereas minority languages are learnt as a first or second language (pp. 16-17). Secondly, language activities are not always as relevant at lower language levels. Thirdly, linguistic situations, such as touristic ones, are not necessarily relevant to the LCTL.

\section{Discussion}

The SpeakApps project is aimed at enhancing the oral language competencies of language learners and delivering support to teachers by providing access to

3. For further information see http://www.teg.ie. 
contextualised task-based activities and resources via the SpeakApps OER. It can be accessed via the SpeakApps platform, and tasks have been developed in the project's target languages using the CEFR as a developmental framework. Tasks developed in the SpeakApps OER can be used with SpeakApps Tools, Langblog, Tandem and Videochat, but they have also been designed to be applied with other technological tools. The SpeakApps OER allows teachers to upload tasks to the repository. Meta-tags are added to the uploaded tasks which provide the following data: the name of the task, the language, the CEFR level, the tool with which the task can be accomplished, and the status of the task. The status of the tasks can be work in progress, published, in pilots, evaluated, and revision requested. Tasks can be developed individually or can make up components of larger activities or projects. The SpeakApps project is currently in its second iteration with the objective of further developing the tasks and the OERs, and to disseminate the project results through workshops and seminars. Whilst engaged in task development, workshops and discussing task creation with teachers of Irish, the following issues came to light in relation to using the OER and the CEFR.

\subsection{Assessment and the CEFR}

Teachers considered that the tasks in the SpeakApps OER could be used for assessment purposes, summative or formative or a combination of both. Increasingly, institutional stakeholders in Ireland require that language qualifications be equated to the CEFR, e.g. registration with The Teaching Council of Ireland or matriculation on postgraduate teaching-oriented courses. To ensure criterion-related validity of tasks, an inventory of the forms, morphosyntactic elements, and phonetic and intonation skills needs to be prescribed to the various levels of the CEFR in Irish. This exercise would be of particular use to language teachers in their selection of tasks, but also as part of a valid and transparent assessment process.

\subsection{Task-based language learning and task creation}

Task-based learning should facilitate a learner's current and future communicative needs (Byram, 2004). The SpeakApps OER contains task-based activities and projects. It is difficult to create a varied range of tasks in the absence of a task-based needs analysis of the Irish language sector, and indeed to reflect the socio-linguistic circumstances of the language. An adaptation of the CEFR with illustrations of the type of language activities learners should be engaged in and the principal domains in which the language is used would underpin task creating and contribute to the integrity and viability of the OER. 


\section{Conclusions}

It is acknowledged that the CEFR provides a comprehensive framework to develop, assess and benchmark language competency. This paper has not sought to engage with the limitations of the framework as identified in the existent literature; rather, it identifies the challenges faced by one LCTL in the application of the framework and the development of tasks for the SpeakApps OER during the project. The issues highlighted are not uniquely associated with the OER and CEFR, but can also be considered as relating to the socio-linguistic status of this particular LCTL. The issues relating to the application of the CEFR to the Irish context could be addressed with the adaptation of the CEFR's Common Reference Levels to take into account an LCTL's socio-linguistic context, with the provision of clear illustrative descriptors so that teachers of LCTLs can optimise OERs and other CALL tools more effectively for learners. This paper concludes that a national level project is needed to engage in such an endeavour.

Acknowledgements. The SpeakApps project was funded by the Lifelong Learning Programme of the European Commission. The paper reflects the views of the authors, and the European Commission cannot be held responsible for any use which may be made of the information contained herein.

\section{References}

Blyth, C. (2013). LCTLs and technology: The promise of open education. Language Learning \& Technology, 17(1), 1-6.

Byram, M. (2004). Routledge encyclopedia of language teaching and learning. New York: Routledge.

Council of Europe. (2001). Common European Framework of Reference for Languages: Learning, teaching, assessment. Cambridge: Cambridge University Press.

D'antoni, S. (2009). Open educational resources: Reviewing initiatives and issues. Open Learning: The Journal of Open, Distance and e-Learning, 24(1), 3-10. doi:10.1080/ 02680510802625443

Gimeno, A., Ó Dónaill, C., \& Zygmantaite, R. (Eds). (2013). Clilstore Guidebook for Teachers. Project: Tools for CLILTeachers. Retrieved from http://www.languages.dk/archive/tools/ guides/ClilstoreGuidebook.pdf

Lotti, B. (2007). Investigation into the use of the common European framework of reference for languages in regional and minority language education. Mercator: European Research Centre on Multilingualism and Language Learning. Retrieved from http://goo.gl/Kr6oey

Martinez, M. (2010). How a new generation of teachers will change schools. The Phi Delta Kappan, 91(7), 74-75. doi: 10.1177/003172171009100716 
NQAI. (2007, December). Towards the establishment of a relationship between the common European framework of reference for languages and the national framework of qualifications. National Qualifications Authority of Ireland. Retrieved from http://www.nqai.ie/documents/ reltionshipbetweenCommonEuroF-W.doc

Teastas Eorpach na Gaeilge. (2006). About TEG. Retrieved from http://teg.ie/english/about teg. htm

The Teaching Council of Ireland. (2013, October). Curricular subject requirements (postprimary) - for persons applying for registration on and after 1 January 2017. Retrieved from http://goo.gl/Q0kd7w

Smith, A. N. \& Casserly, C. M. (2006). The promise of open educational resources. Change, 38(5), 8-17. doi:10.3200/CHNG.38.5.8-17

Walsh, J., \& Nic Eoin, M. (2010). Siollabas nua Gaeilge don chéad bhliain ollscoile. Teagasc na Gaeilge, 9, 13-23. 